\title{
Ausgewählte Anwendungsfelder
}

Nachdem Sie nun viel über Fragearten und Fragekonstruktionen erfahren haben, möchte ich eine Auswahl konkreter systemischer Anwendungen und Beispiele geben. Im Sinne einer übergeordneten Orientierung beziehen sich die folgenden Fragebeispiele auf die fünf zentralen Aspekte systemischen Fragens vom Anfang dieses Essentials.

Natürlich stellt sowohl die Fokussierung auf diese fünf Aspekte als auch die jeweilige Reduktion auf ausgewählte Beispiele eine große Einengung des Fragespektrums dar. Gleichwohl ist eine solche Beschränkung im Rahmen dieses Essentials unumgänglich. 